\title{
Tenotomia do glúteo máximo em artroplastia total do quadril como prevenção de lesão do nervo ciático
}

\section{Tenotomy of the Gluteus Maximus in Total Hip Arthroplasty with Prevention of Sciatic Nerve Injury}

\author{
Leonardo Morais Paiva ${ }^{1,2}$ Karina Maria Alécio de Oliveira ${ }^{1,2}$ Diogo Ranier de Macedo Souto ${ }^{1,2}$ \\ Sílvio Leite de Macedo Neto ${ }^{1,2}$ Nicolay Jorge Bonvine Kircov ${ }^{1,2}$ Anderson Freitas ${ }^{1,2}$ \\ 1 Serviço de Quadril, Hospital Ortopédico e Medicina Especializada, \\ Brasília, DF, Brasil \\ ${ }^{2}$ Hospital de Base do Distrito Federal, Brasília, DF, Brasil \\ Address for correspondence Leonardo Morais Paivaa, Serviço de \\ Quadril, Hospital Ortopédico e Medicina Especializada (HOME), \\ Brasília, DF, Brasil (e-mail: leopmorais@yahoo.com.br).
}

Rev Bras Ortop 2019;54:206-209.

\section{Resumo \\ Palavras-chave \\ - nervo ciático/lesões \\ - artroplastia de quadril \\ - tenotomia/métodos}

Os autores relatam um único caso de artroplastia total de quadril primária complexa em uma paciente do sexo feminino de 34 anos, com dismetria de membros inferiores de $5,5 \mathrm{~cm}$, na qual foi feita tenotomia do glúteo máximo a fim de prevenir lesão do nervo ciático. Tal cirurgia foi feita sob monitoração eletroneurofisiológica dos ramos fibular e tibial do nervo ciático. Foram coletados dados pré-tenotomia, pós-tenotomia e pós-redução artroplástica. Os achados demonstram que a tenotomia do glúteo máximo melhorou a reposta motora do componente fibular do nervo ciático.

The authors report a single case of complex primary hip total arthroplasty in a 34-yearold female patient with a $5.5 \mathrm{~cm}$ lower limb dysmetria, in whom a maximum gluteus tenotomy was performed in order to prevent sciatic nerve injury. The surgery was performed under electroneurophysiological monitoring of the fibular and tibial branches of the sciatic nerve, collecting pretenotomy, posttenotomy, and postarthroplasty reduction data. The findings demonstrate that the maximum gluteus tenotomy improved the motor response of the fibular component of the sciatic nerve.

\section{Introdução}

A artroplastia total do quadril (ATQ) em pacientes com encurtamento do membro inferior é um desafio, além de ser tecnicamente exigente. A prevalência de lesão do nervo após a ATQ varia de 0,3 a 3,7\%. ${ }^{1}$ Diversas causas são relacionadas a esta lesão, tais como alongamento excessivo do nervo, compressão mecânica ou tração por afastamento na abordagem cirúrgica, e a contratura em flexão do quadril. ${ }^{2} \mathrm{~A}$ paralisia do nervo ciático relacionada com a ATQ está entre as complicações mais comuns de neuropatia transoperatória. ${ }^{2,3}$

received

May 15, 2017

accepted

July 13, 2017
Entre uma das principais causas está o alongamento do membro operado quando o encurtamento ultrapassa $4 \mathrm{~cm}$. Estudos a fim de definir fatores de risco para lesão do ciático em pacientes submetidos a artroplastia apresentam o encurtamento $\geq 4 \mathrm{~cm}$ como importante fator isolado. ${ }^{3}$

Devido ao risco de lesão nervosa em membros encurtados, a monitoração neurofisiológica por meio de potencial evocado motor, potencial evocado sensitivo e eletromiografia espontânea é essencial para o controle intraoperatório a fim de prevenir a lesão neurológica. ${ }^{4}$ A monitoração dos nervos em tempo real durante o procedimento cirúrgico tem sido
Copyright $(2019$ by Sociedade Brasileira License terms de Ortopedia e Traumatologia. Published by Thieme Revnter Publicações Ltda, Rio de Janeiro, Brazil 
defendida durante o tratamento de fraturas acetabulares e artroplastias totais complexas do quadril para evitar lesão do nervo ciático. Alguns estudos mostraram que é possível e apropriado usar este método durante a cirurgia complexa de quadril, é eficaz para alertar o cirurgião a possibilidade de lesão do nervo. ${ }^{4,5}$

A correlação anatômica entre o tendão do glúteo máximo e o nervo ciático já é descrita como fator etiológico de dor glútea profunda. Tal patologia é uma entidade caracterizada por dor na região do quadril ou na região posterior da coxa e tem como causas alterações radiculares por compressões discogênicas ou compressões radiculares por causas não discogênicas; uma delas é a compressão no espaço subglúteo, fato esse ratificado por recentes tratamentos de descompressão do nervo ciático por via endoscópica com a feitura da tenotomia do glúteo máximo. ${ }^{5}$

Com isso, descrever o padrão eletrofisiológico intraoperatório do nervo ciático em um caso complexo de coxartrose com dismetria $>4 \mathrm{~cm}$, tratada com ATQ associada à tenotomia do glúteo máximo, pode direcionar futuros produtos científicos de maior nível de evidência a fim de nortear um padrão de conduta e evitar a lesão neurológica em tal procedimento, uma vez que foi notada melhoria eletrográfica do potencial evocado motor do ramo fibular.

\section{Relato de caso}

Paciente do sexo feminino, 34 anos, diagnosticada com coxartrose bilateral, apresentava, no quadril esquerdo, ao raio-X da bacia, coxartrose grau IV de Tonnis (-Fig. 1). A paciente apresentava encurtamento de $5,5 \mathrm{~cm}$ do membro inferior esquerdo aferido por escanometria, além de claudicação, dor lombar, dor no joelho. Limitação funcional do quadril esquerdo, Harris Hip Score (HHS) de 52 pontos.

Programado tratamento cirúrgico para ATQ à esquerda, a paciente foi orientada sobre os riscos relacionadas à cirurgia e principalmente sobre o risco de lesão do nervo ciático.

A paciente foi submetida a raquianestesia para analgesia com codeína, sem bloqueio motor. Posicionada em decúbito lateral direito, os eletrodos de monitoração eletroneurofi-

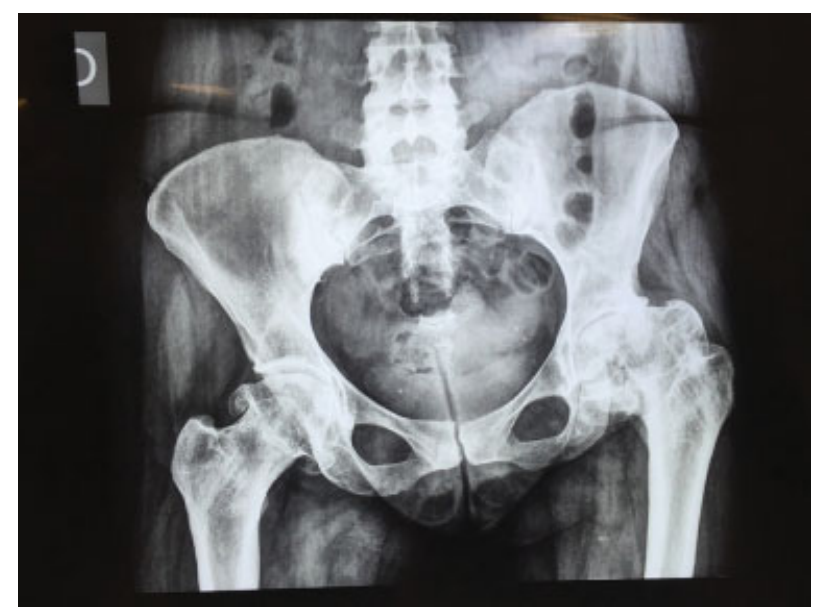

Fig. 1 Radiografia em anteroposterior da bacia - coxartrose bilateral, demonstra encurtamento de membro inferior esquerdo. siológica foram posicionados e sucessivos testes de potenciais evocados foram feitos - sensitivo, motor, e eletromiográfico - espontânea contínua, a fim de avaliar as funções dos ramos fibular e tibial do nervo ciático esquerdo, com uso de meios de controle de artefatos biológicos e não biológicos. À avaliação neurofisiológica inicial, a paciente apresentou linha de base anestésica com ausência de atividade desnervatória em repouso à eletromiografia espontânea nos estudos dos músculos tibial anterior (M1), gastrocnêmio (M2), fibular (M3) e extensor curto dos dedos (M4) do membro afetado, na fase pré-tenotomia (-Fig. 2a). Feito acesso posterior de Kocher-Langenbeck, não houve alteração do padrão eletrofisiológico da linha de base anestésica. Com o tendão do glúteo máximo dissecado e visualizado, foi feita a tenotomia a $1 \mathrm{~cm}$ de sua base insercional, previamente à osteotomia do colo femoral. Evidenciou-se ganho de amplitude $>50 \%$ dos potenciais referentes ao músculo fibular e extensor curto dos dedos em relação à linha de base anestésica, pós-tenotomia (-Fig. 2b). Tal padrão eletroneurofisiológico foi mantido durante todo o procedimento cirúrgico, até após a redução artroplástica.

Após a finalização de todo o ato cirúrgico, foi solicitada à paciente a mobilidade ativa de dorsoflexão plantar e extensão do hálux, feita normalmente. A avaliação clínica da dismetria dos membros inferiores ainda na sala operatória foi aferida, por meio de equalização dos maléolos mediais, após correção de inclinação pélvica, e foi observada a equalização dos membros inferiores (-Fig. 3).

O procedimento cirúrgico durou 93 minutos e foi contado a partir do início do posicionamento da monitoração eletrofisiológica até a sutura da pele. Não houve alterações clínicas da paciente durante a cirurgia nem intercorrências técnicas na implantação protética.

\section{Discussão}

A dismetria dos membros inferiores que ultrapassa $4 \mathrm{~cm}$ tem elevada incidência de lesão neurológica, quando é feita ATQ. ${ }^{5}$

Por meio do presente relato, os autores descrevem a possibilidade de uma técnica protetiva a fim de diminuir tal incidência.

O procedimento de monitoração eletrofisiológica intraoperatória serve para análise das funções dos nervos e dos músculos em tempo real, dá informações preliminares do estado neuromuscular do paciente em pré-operatório imediato e, durante a cirurgia de ATQ em paciente com dismetria, já tem sua importância ratificada na literatura, fato confirmado pelo aqui exposto e suplementado de informações referentes a padrões eletrofisiológicos de melhoria do potencial evocado motor.

No caso em pauta, as alterações da linha de base (achados iniciais) foram revertidas após a tenotomia, importante para: respaldar o cirurgião quanto às alterações iniciais, não responsabilizar o cirurgião quanto a estes achados em pósoperatório, informar ao cirurgião as condições iniciais do acometimento inervatório do quadril por meio da avaliação neuromuscular dos músculos correspondentes a esta inervação, comprovar que a tenotomia foi eficaz na preservação e 
A
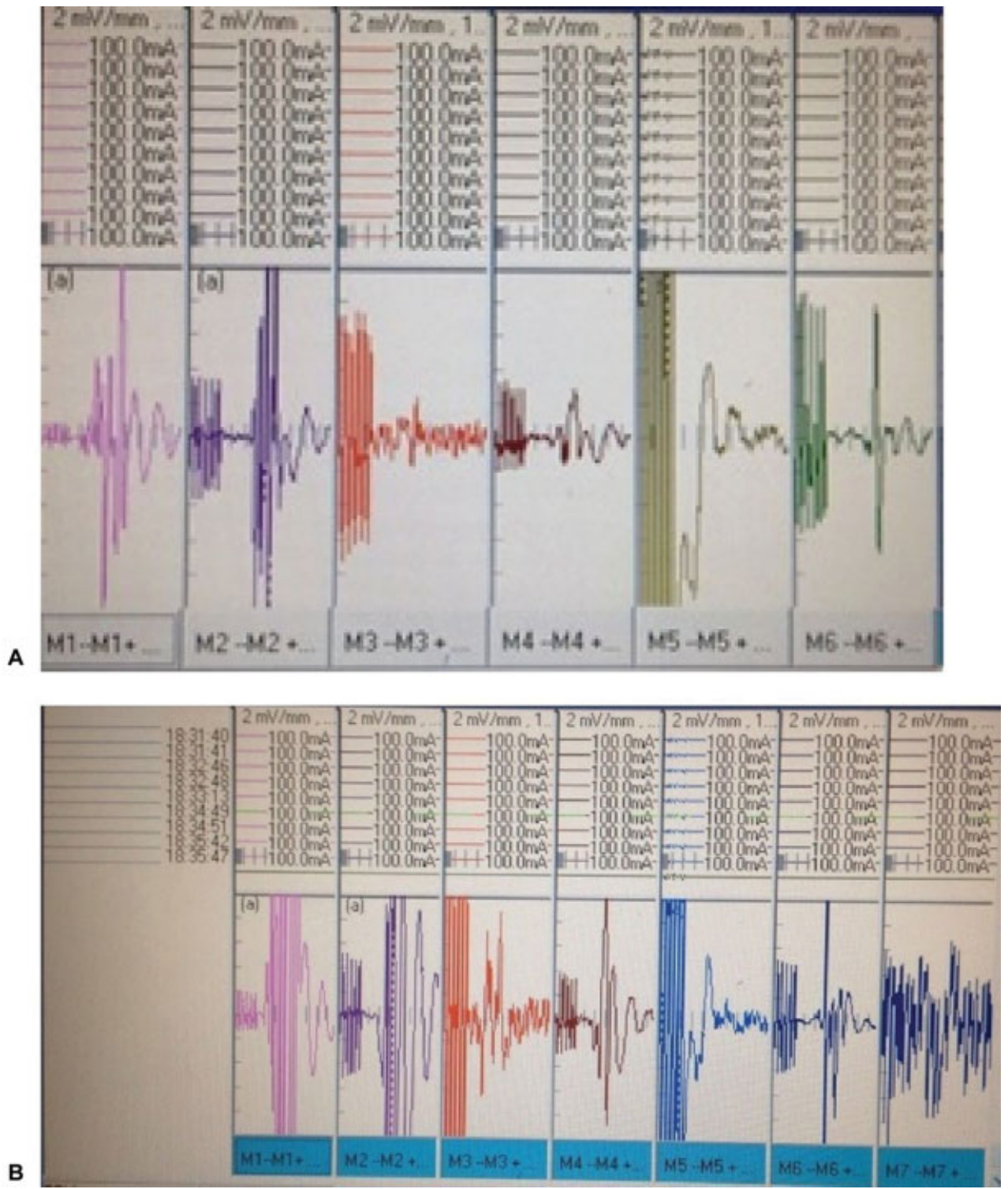

Fig. 2 A, Pré-tenotomia: gráfico dos potenciais evocados motores, nos quais M3 e M4 correspondem aos músculos fibular e extensor curto dos dedos, respectivamente. A amplitude das ondas em M1, M2 e M3 estão de $10 \mathrm{mV}, 2 \mathrm{mV}$ e $3 \mathrm{mV}$, respectivamente (solicitar amplitude de onda de M1 e M4). B, Pós-tenotomia: gráfico de avaliação eletrofisiológica de M1 a M6 com apresentação de M7. As ondas M1 e M2 passaram a ter 7 e $9 \mathrm{mV}$, respectivamente.

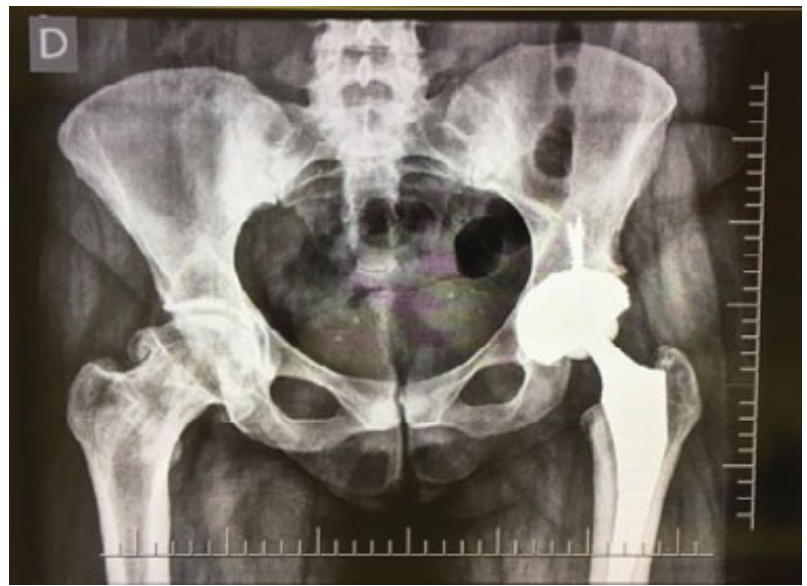

Fig. 3 Foto demonstrativa de dismetria residual na avaliação maleolar no pós-operatório. na recuperação da função das estruturas comprometidas e comprovar que a técnica cirúrgica aplicada naquele momento não foi nociva ao paciente.

A tenotomia do glúteo máximo é descrita para o tratamento de dor glútea profunda, da qual uma das causas é a compressão não discogênica (compressão do nervo ciático). ${ }^{5}$ A descrição deste procedimento como medida protetiva à lesão do nervo ciático durante a ATQ (conforme apresentado pelos autores) necessita de estudos de maior evidência científica. No entanto, os resultados eletroneurofisiológicos aqui apresentados nos avalizam a estimular grandes centros na feitura de estudos clínicos prospectivos a fim de ratificar o resultado aqui apresentado.

\section{Conflitos de Interesses}

Os autores declaram não haver conflitos de interesses. 


\section{Referências}

1 Higuchi Y, Hasegawa Y, Ishiguro N. Leg lengthening of more than 5 $\mathrm{cm}$ is a risk factor for sciatic nerve injury after total hip arthroplasty for adult hip dislocation. Nagoya J Med Sci 2015;77(03): 455-463

2 Farrell CM, Springer BD, Haidukewych GJ, Morrey BF. Motor nerve palsy following primary total hip arthroplasty. J Bone Joint Surg Am 2005;87(12):2619-2625
3 Sutter M, Hersche O, Leunig M, Guggi T, Dvorak J, Eggspuehler A. Use of multimodal intra-operative monitoring in averting nerve injury during complex hip surgery. J Bone Joint Surg Br 2012;94(02):179-184

4 Pring ME, Trousdale RT, Cabanela ME, Harper CM. Intraoperative electromyographic monitoring during periacetabular osteotomy. Clin Orthop Relat Res 2002;(400):158-164

5 Martin HD, Reddy M, Gómez-Hoyos J. Deep gluteal syndrome. J Hip Preserv Surg 2015;2(02):99-107 